\title{
Review of catumaxomab in the treatment of malignant ascites
}

\author{
This article was published in the following Dove Press journal: \\ Cancer Management and Research \\ 4 November 2010 \\ Number of times this article has been viewed
}

\section{Martin Sebastian \\ Department of Internal Medicine III, Hematology, Medical Oncology, and Pneumology, University Medical Center of the Johannes Gutenberg University, Mainz, Germany}

Correspondence: Martin Sebastian Department of Internal Medicine III, Hematology, Medical Oncology, and Pneumology, University Medical Center of the Johannes Gutenberg University Mainz, Langenbeckstr I, 55I3I Mainz, Germany

Tel +49 6I3 II7 54I7

Fax +496131176680

Email martin.sebastian@ukmainz.de

\begin{abstract}
Malignant ascites is frequently found with various solid tumors, and no established treatment options exist, apart from symptomatic paracentesis. Catumaxomab, a trifunctional bispecific monoclonal antibody, has two binding specificities directed to epithelial cell adhesion molecule (EpCAM) and the $\mathrm{T}$ cell antigen CD3. With its Fc-fragment, catumaxomab additionally binds accessory cells, including dendritic cells, macrophages, and natural killer cells. The trifunctional approach thus leads to a major histocompatibility complex-unrestricted but specific killing of epithelial tumor cells without need for preactivation or external costimulation. Because EpCAM is expressed in most solid tumors, but not in tissue of mesothelial origin, intraperitoneal treatment with catumaxomab is tumor-specific. Intraperitoneal treatment with catumaxomab resulted in a significant prolongation of puncture-free survival in patients with malignant ascites due to epithelial cancer. Catumaxomab has been approved in Europe for the intraperitoneal treatment of malignant ascites in patients with EpCAM-positive epithelial tumors where standard therapy is not available or no longer feasible.
\end{abstract}

Keywords: catumaxomab, ascites, epithelial cell adhesion molecule

\section{Introduction}

Peritonitis carcinomatosa indicates the presence of malignant cells in the peritoneal cavity, and is a well known complication of a number of malignant diseases. As a result, so-called malignant ascites develops. Malignant ascites is characterized by positive cytology of malignant cells. Impaired lymphatic drainage by occlusion of the lymphatic vessels and increased fluid production causes the accumulation of malignant ascites in the peritoneum. ${ }^{1}$ Clinical manifestations include symptoms of abdominal pain, obstruction, fatigue, and abdominal swelling.

In their retrospective analysis of 209 patients with malignant ascites, Ayantunde et al found a median survival time of 5.7 months after diagnosis of ascites. Independent negative prognostic factors were type of cancer, liver metastasis, and low serum albumin, and, in contrast, patients with ovarian cancer had a favorable prognosis. ${ }^{2}$

Treatment options are symptomatic, and the most common is paracentesis or surgical treatment, including peritoneovenous shunting. Systemic and local treatment options include systemic chemotherapy, intraperitoneal chemotherapy, or therapy with radioisotopes. Additionally, the vascular endothelial growth factor antibody bevacizumab is currently being tested in clinical studies to treat and prevent malignant ascites. $^{3}$ 


\section{Catumaxomab}

\section{Mode of action}

Catumaxomab (anti-EpCAM $\times$ anti-CD3) is a hybrid, hybridoma-derived, trifunctional, monoclonal bispecific antibody, combining two half-antibodies of mouse IgG2a and rat $\mathrm{IgG} 2 \mathrm{~b}$ that represent homologous immunoglobulin subclasses. Preclinical studies have shown the following three events to occur, demonstrating the trifunctional mode of action of the drug:

- One antigen binding site, the mouse $\operatorname{IgG} 2 \mathrm{a}$, recognizes the tumor-specific antigen ${ }^{4}$

- The other antigen binding site (rat IgG2b) binds to CD3, part of the $\mathrm{T}$ cell receptor complex ${ }^{5,6}$

- The Fc-fragment binds to FcyR Type I and III positive cells (eg, macrophages, dendritic cells, and natural killer cells) but not to inhibitory Type II FcyR (located on, eg, B cells). ${ }^{7}$

The stimulation of immune cells is demonstrated by production of cytokines, including interleukin (IL)-1 $\beta$, IL-2, IL-6, IL-12, and the dendritic cell cytokine 1. Activated accessory cells, including macrophages and dendritic cells, induce several costimulatory signals, eg, via CD40-CD40L to $\mathrm{T}$ cells to prevent $\mathrm{T}$ cell anergy. The simultaneous activation of $\mathrm{T}$ cells and accessory immune cells, and their mutual stimulation, leads to specific tumor cell killing by induction of apoptosis, release of cytokines, and perforinmediated lysis, as well as antibody-dependent cellular cytotoxicity. Crucial in this process is the combination of the two potent immunoglobulin isotypes, mouse $\operatorname{IgG} 2 \mathrm{a}$ and rat $\mathrm{IgG} 2 \mathrm{~b}$, which, in contrast with other reported combinations, not only bind but also activate accessory cells. The trifunctional approach thus leads to major histocompatibility complex-unrestricted but specific killing of tumor cells without need for preactivation or external costimulation ${ }^{5,8}$ (see Figure 1).

EpCAM is a Type I transmembrane glycoprotein that mediates $\mathrm{Ca}^{2+}$-independent homophilic cell adhesions. ${ }^{9}$ In humans, EpCAM is expressed only in epithelium and neoplasms derived from epithelia. ${ }^{10}$ EpCAM is also strongly expressed in carcinomas of various origins, including colon, rectum, gastric, ovarian, esophagus, lung, pancreas, breast, head, and neck. ${ }^{11-13}$ Because of the wide expression on tumor cells, EpCAM is considered a tumor-associated antigen, and innovative immunotherapeutic approaches targeting EpCAM are of special interest. EpCAM expression is a negative prognostic marker for overall survival in patients suffering from either nodal-positive or node-negative breast cancer. Schmidt et al demonstrated that EpCAM overexpression was independently associated with poor survival in node-negative patients. This effect was particularly strong in the subgroup of triple-negative breast cancer, making EpCAM an attractive therapeutic target in this patient population. ${ }^{14,15}$

EpCAM has a direct impact on cell cycle and proliferation, and the ability to upregulate the proto-oncogene, c-myc, and cyclin A/E rapidly. Furthermore, EpCAM weakens cadherinmediated cell adhesion, and thereby modulates proliferation, differentiation, and tissue maintenance. ${ }^{16}$ Blocking of EpCAM leads to a decrease in proliferation and metabolism in human carcinoma cells. ${ }^{17}$ Recently, Maetzel et al demonstrated how EpCAM affects nuclear function by shedding of its ectodomain, EpEX, and nuclear translocation of its intracellular domain, EpICD, dependent on the presence of tumor necrosis factor-alpha-converting enzyme (TACE, ADAM17) and presenilin-2. ${ }^{18}$ Furthermore, Lindhofer et al showed elimination of putative EpCAM-positive cancer stem cells (CD 133+/EpCAM+) in patients with malignant ascites

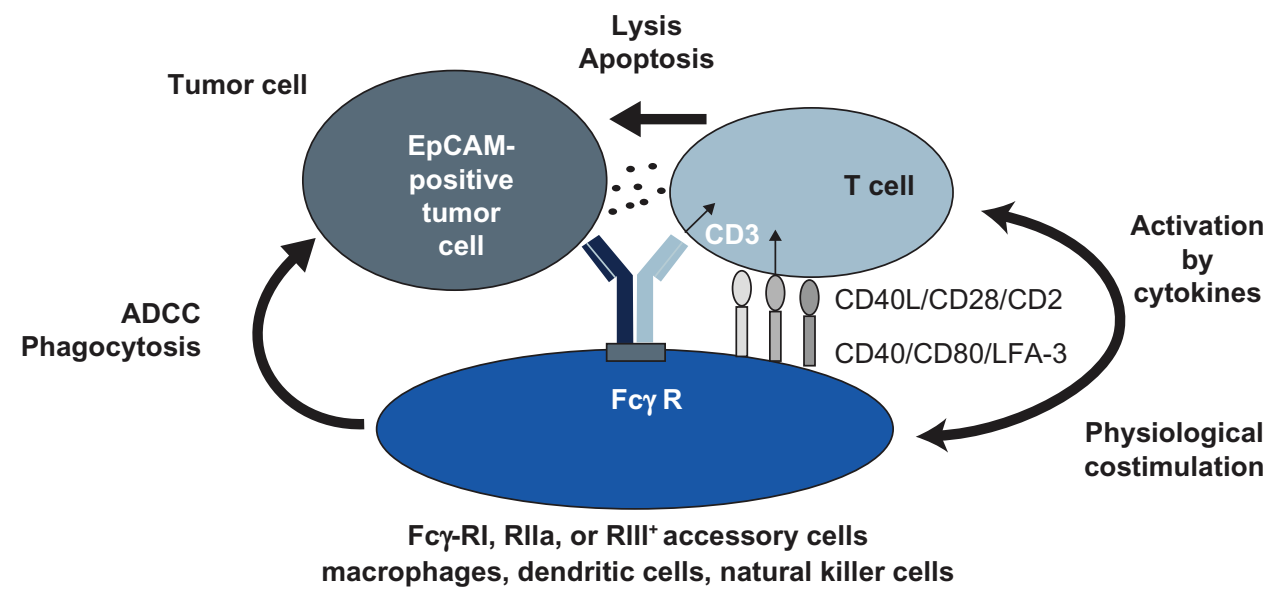

Figure I Proposed mode of action of catumaxomab. 
treated with catumaxomab. ${ }^{19}$ Recently Hirschhaeuser et al demonstrated a strong, dose-dependent effect of catumaxomab on multicellular tumor spheroids of human EpCAM-positive FaDu tumor cells when cocultured with human peripheral blood monocytes in terms of volume reduction and infiltration of immune cells. ${ }^{20}$

\section{Intraperitoneal administration}

The first reported clinical pilot study treated eight patients with malignant ascites by intraperitoneal application of catumaxomab or ertumaxomab binding EpCAM or human epidermal growth receptor $2 /$ neu antigen on tumor cells, respectively. Treatment consisted of four to six applications within nine to 23 days, using a total amount of 145-940 $\mu \mathrm{g}$ of the antibody. Seven of eight patients required no further paracentesis during follow-up or until death, with a mean paracentesis-free interval of 38 weeks. Complete elimination of tumor cells in ascites was seen at total doses of 40-140 $\mu$ g. Clinical response with disappearance of ascites accumulation was correlated with elimination of tumor cells $(P=0.0014){ }^{21}$

In a Phase I/II study reported by Burges, patients with malignant ascites due to ovarian cancer were treated with escalating intraperitoneal doses of catumaxomab. The maximum tolerated dose was defined as 10, 20, 50, 200, and $200 \mu \mathrm{g}$ on days $0,3,6,9$, and 13. The dose-limiting toxicities were large bowel obstruction Common Toxicity Criteria Grade 3 and gamma glutamyl transferase elevation Grade 4. All patients had treatment-emergent adverse events, with fever, nausea, vomiting, abdominal pain, lymphopenia, and general pain being the most common events. In terms of efficacy, 22 of 23 patients did not require any further paracentesis during a follow-up period of up to 37 days. The authors concluded that a dose regimen of 10, 20, 50, and $150 \mu \mathrm{g}$ would be the recommended treatment schedule for further investigation. ${ }^{22}$

This led to a pivotal Phase II/III study in patients with symptomatic malignant ascites secondary to epithelial cancers requiring symptomatic therapeutic paracentesis. The study compared paracentesis with intraperitoneal catumaxomab versus paracentesis alone in a two-arm, open-label, randomized trial. The primary endpoint was puncture-free survival, defined as the time to first need for therapeutic puncture or death after treatment. Secondary endpoints were time to next paracentesis, ascites signs defined by the patient, ascites signs defined by the investigator, and overall survival. The investigators were to follow an algorithm when a paracentesis was indicated (ascites $>1 \mathrm{~L}$ as assessed by a computed tomography scan and signs and symptoms of ascites assessed by the investigator using physical examination and a patient questionnaire) to ensure a comparable decision on when to perform paracentesis by the different investigators in the different treatment arms. Patient in the paracentesis-only treatment group were allowed to cross over to catumaxomab treatment if they still fulfilled the inclusion and exclusion criteria, and had had at least two paracenteses after day 0 of the study. The percentage and outcome of the crossover patients were not reported, although they might influence the secondary endpoint of overall survival. Treatment consisted, as recommended, of four constant-rate intraperitoneal infusions at doses of 10 , 20,50 , and $150 \mu \mathrm{g}$ of catumaxomab on days $0,3,7$, and 10 . The antibody was administered via intraperitoneal catheter in an inpatient setting, and the control group was treated with a paracentesis. Toxicity was as expected, with predominantly cytokine-release-like symptoms, including pyrexia (in $60.5 \%$ of patients), nausea, and vomiting. Ileus was reported in $6.4 \%$ of the patients treated with catumaxomab. There were no treatment-related deaths. In total, 258 patients were randomized, of whom 170 received catumaxomab and paracentesis and 88 received paracentesis alone. One hundred and twenty-nine patients had ovarian cancer, and 129 patients suffered from nonovarian cancer, mostly gastric cancer $(n=66)$. The primary endpoint of puncture-free survival was significantly prolonged in catumaxomab patients in both strata (ovarian: 52 versus 11 days, and nonovarian cancer: 37 versus 14 days, $P<0.0001$, respectively) as well as in the pooled analysis (46 versus 11 days). The secondary endpoint of median overall survival was not prolonged in the pooled analysis (72 days for catumaxomab versus 68 days for paracentesis only, $P=0.0846)$ as well as in the stratified groups. Subgroup analysis showed a significant $(P=0.0313)$ survival benefit for catumaxomab in the gastric cancer patients (71 versus 44 days). The authors concluded that the treatment regimen demonstrated a clinically relevant benefit in patients with malignant ascites from epithelial cancer. ${ }^{23}$

\section{Summary}

Catumaxomab, given intraperitoneally in ascending, repetitive doses, prolongs puncture-free survival in patients with malignant ascites. Side effects are explained by the mode of action of the drug and are usually reversible. Common side effects with intraperitoneal treatment include cytokine releaserelated symptoms, like fever, chills, nausea, and vomiting.

\section{Disclosure}

The author has received lecture fees from and previously consulted for Fresenius Biotech. 


\section{References}

1. Tamsma J. The pathogenesis of malignant ascites. Cancer Treat Res. 2007;134:109-118.

2. Ayantunde AA, Parsons SL. Pattern and prognostic factors in patients with malignant ascites: A retrospective study. Ann Oncol. 2007;18(5): 945-949.

3. El-Shami K, Elsaid A, El-Kerm Y. Open-label safety and efficacy pilot trial of intraperitoneal bevacizumab as palliative treatment in refractory malignant ascites. J Clin Oncol. 2007;25 Supp1 18:9043.

4. Schmitt M, Schmitt A, Reinhardt P, et al. Opsonization with a trifunctional bispecific (alphaCD3 $\mathrm{x}$ alphaEpCAM) antibody results in efficient lysis in vitro and in vivo of EpCAM positive tumor cells by cytotoxic T lymphocytes. Int J Oncol. 2004;25(4):841-848.

5. Ruf P, Gires O, Jager M, Fellinger K, Atz J, Lindhofer H. Characterisation of the new EpCAM-specific antibody HO-3: Implications for trifunctional antibody immunotherapy of cancer. Br J Cancer. 2007; 97(3):315-321.

6. Zeidler R, Reisbach G, Wollenberg B, et al. Simultaneous activation of $\mathrm{T}$ cells and accessory cells by a new class of intact bispecific antibody results in efficient tumor cell killing. J Immunol. 1999;163(3): 1246-1252.

7. Zeidler R, Mysliwietz J, Csanady M, et al. The Fc-region of a new class of intact bispecific antibody mediates activation of accessory cells and NK cells and induces direct phagocytosis of tumour cells. Br J Cancer. 2000;83(2):261-266.

8. Riesenberg R, Buchner A, Pohla H, Lindhofer H. Lysis of prostate carcinoma cells by trifunctional bispecific antibodies (alpha EpCAM x alpha CD3). J Histochem Cytochem. 2001;49(7):911-917.

9. Litvinov SV, Velders MP, Bakker HA, Fleuren GJ, Warnaar SO. Ep-CAM: A human epithelial antigen is a homophilic cell-cell adhesion molecule. J Cell Biol. 1994;125(2):437-446.

10. Balzar M, Winter MJ, de Boer CJ, Litvinov SV. The biology of the 17-1A antigen (Ep-CAM). J Mol Med. 1999;77(10):699-712.

11. Osta WA, Chen Y, Mikhitarian K, et al. EpCAM is overexpressed in breast cancer and is a potential target for breast cancer gene therapy. Cancer Res. 2004;64(16):5818-5824.

12. Went P, Vasei M, Bubendorf L, et al. Frequent high-level expression of the immunotherapeutic target Ep-CAM in colon, stomach, prostate and lung cancers. Br J Cancer. 2006;94(1):128-135.
13. Went PT, Lugli A, Meier S, et al. Frequent EpCam protein expression in human carcinomas. Hum Pathol. 2004;35(1):122-128.

14. Schmidt M, Hasenclever D, Schaeffer M, et al. Prognostic effect of epithelial cell adhesion molecule overexpression in untreated nodenegative breast cancer. Clin Cancer Res. 2008;14(18):5849-5855.

15. Schmidt M, Petry IB, Bohm D, et al. Ep-CAM RNA expression predicts metastasis-free survival in three cohorts of untreated node-negative breast cancer. Breast Cancer Res Treat. 2010 Mar 30. [Epub ahead of print].

16. Litvinov SV, Balzar M, Winter MJ, et al. Epithelial cell adhesion molecule (Ep-CAM) modulates cell-cell interactions mediated by classic cadherins. J Cell Biol. 1997;139(5):1337-1348.

17. Munz M, Kieu C, Mack B, Schmitt B, Zeidler R, Gires O. The carcinoma-associated antigen EpCAM upregulates c-myc and induces cell proliferation. Oncogene. 2004;23(34):5748-5758.

18. Maetzel D, Denzel S, Mack B, et al. Nuclear signalling by tumourassociated antigen EpCAM. Nat Cell Biol. 2009;11(2):162-171.

19. Lindhofer H, Schoberth A, Pelster D, Hess J, Herold J, Jager M. Elimination of cancer stem cells (CD133+/EpCAM+) from malignant ascites by the trifunctional antibody catumaxomab: Results from a pivotal phase II/III study. J Clin Oncol. 2009;27 Suppl 15:3014.

20. Hirschhaeuser F, Walenta S, Mueller-Klieser W. Efficacy of catumaxomab in tumor spheroid killing is mediated by its trifunctional mode of action. Cancer Immunol Immunother. 2010;59(11):1675-1684.

21. Heiss MM, Strohlein MA, Jager M, et al. Immunotherapy of malignant ascites with trifunctional antibodies. Int $J$ Cancer. 2005;117(3): 435-443.

22. Burges A, Wimberger P, Kumper C, et al. Effective relief of malignant ascites in patients with advanced ovarian cancer by a trifunctional antiEpCAM x anti-CD3 antibody: A phase I/II study. Clin Cancer Res. 2007;13(13):3899-3905.

23. Heiss MM, Murawa P, Koralewski P, et al. The trifunctional antibody catumaxomab for the treatment of malignant ascites due to epithelial cancer: Results of a prospective randomized phase II/III trial. Int J Cancer. 2010;127(9):2209-2221.
Cancer Management and Research

\section{Publish your work in this journal}

Cancer Management and Research is an international, peer-reviewed open access journal focusing on cancer research and the optimal use of preventative and integrated treatment interventions to achieve improved outcomes, enhanced survival and quality of life for the cancer patient. The journal welcomes original research, clinical \& epidemiological

\section{Dovepress}

studies, reviews \& evaluations, guidelines, expert opinion \& commentary, case reports \& extended reports. The manuscript management system is completely online and includes a very quick and fair peerreview system, which is all easy to use. Visit http://www.dovepress.com/ testimonials.php to read real quotes from published authors. 